\title{
The Oxidation Behaviour of Alloys Based on the Ni-Co-Al-Ti-Cr System
}

\author{
K. A. Christofidou' ${ }^{1}$ N. G. Jones ${ }^{1}$ - M. C. Hardy ${ }^{2}$ • \\ H. J. Stone ${ }^{1}$ (D)
}

Received: 6 November 2015/Revised: 3 December 2015/Published online: 22 December 2015

(C) The Author(s) 2015. This article is published with open access at Springerlink.com

\begin{abstract}
The isothermal oxidation behaviour of a series of quinary $\mathrm{Ni}-\mathrm{Co}-\mathrm{Al}-$ Ti-Cr alloys were studied at $800{ }^{\circ} \mathrm{C}$. Alloys with higher $\mathrm{Cr}$ concentrations exhibited lower mass gain after 100-h exposure, as did the alloys richest in $\mathrm{Ni}$ and $\mathrm{Al}$ for a given $\mathrm{Cr}$ concentration. Extensive internal oxidation and nitridation was also observed in all alloys, except those containing the highest concentrations of $\mathrm{Ni}$ and Al. All alloys studied generated continuous chromium oxide layers, beneath which alumina particles were observed. Compositional analysis of the subscales identified shallower $\mathrm{Cr}$ concentration gradients in alloys containing equiatomic levels of $\mathrm{Ni}$ and $\mathrm{Co}$, suggesting increased availability of $\mathrm{Cr}$ in the alloy. Thermodynamic calculations confirmed that these alloys contained higher concentrations of $\mathrm{Cr}$ in their $\gamma$ matrices as a result of a combination of both the elemental partitioning behaviour and the increased mole fraction of $\gamma^{\prime}$ precipitates forming in the alloy.
\end{abstract}

Keywords Nickel-base superalloy $\cdot$ Oxidation $\cdot$ SEM $\cdot$ TGA $\cdot$ EDX

\section{Introduction}

The worldwide desire to reduce aerospace emissions requires the next generation of gas turbine engines to operate at higher temperatures and faster rotational speeds. Such operating conditions are beyond the capability of current polycrystalline

Electronic supplementary material The online version of this article (doi:10.1007/s11085-015-9606-8) contains supplementary material, which is available to authorized users.

H. J. Stone

hjs1002@cam.ac.uk

1 Department of Materials Science and Metallurgy, University of Cambridge, 27 Charles Babbage Road, Cambridge CB3 0FS, UK

2 Rolls-Royce plc, Moor Lane, PO Box 31, Derby DE24 8BJ, UK 
Ni-based superalloys and, therefore, new alloys capable of operating at temperatures as high as $800{ }^{\circ} \mathrm{C}$, are required. Such polycrystalline Ni-based superalloys usually employ high concentrations of $\mathrm{Cr}$ to allow the formation of a continuous chromia $\left(\mathrm{Cr}_{2} \mathrm{O}_{3}\right)$ scale and achieve the requisite environmental resistance. In addition, these alloys also include a range of other elemental additions to further improve their properties. Recently, elevated levels of Co and Ti have been shown to be beneficial, providing improved high temperature strength and creep resistance [1, 2]. However, in addition to their mechanical performance, the environmental resistance of these alloys is also critical, as surface degradation can accelerate fatigue crack initiation during high temperature exposure, leading to premature failure [3-5]. Yet, to date, the influence of elevated $\mathrm{Co}$ and $\mathrm{Ti}$ concentrations on the oxidation characteristics of Ni-based superalloys has not been systematically studied.

The oxidation behaviours of simple binary and ternary $\mathrm{Ni}$ - and Co-based alloys, as well as those of more complex, commercially available superalloys, are well established [6-14]. Previous studies on $\mathrm{Ni}-\mathrm{Cr}$ and $\mathrm{Co}-\mathrm{Cr}$ binary alloys have determined that a concentration of $\mathrm{Cr}$ in excess of $10 \mathrm{wt} . \%$ is required to allow the formation of a protective chromia layer [6]. The parabolic growth rate of this oxide has been shown to decrease as the concentration of $\mathrm{Cr}$ increases, reaching a minimum around 20 - $25 \mathrm{wt} . \%[15,16]$. The presence of $\mathrm{Al}$ in the alloy has also been shown to improve the oxidation characteristics of chromia scale forming alloys by increasing the Cr activity [17].

Whilst alloying with $\mathrm{Ti}$ is known to confer significant benefits to the mechanical properties of superalloys by increasing the APB energy and hardening the $\gamma^{\prime}$ [18], it has been reported to give rise to differing effects on the oxidation behaviour of $\mathrm{Ni}-\mathrm{Cr}$ and $\mathrm{Co}-\mathrm{Cr}$ based alloys. Nagai et al. [19], demonstrated that the oxidation rate of $\mathrm{Ni}-20 \mathrm{Cr}$ wt. \% alloys increased significantly with the addition of $\mathrm{Ti}$, as did the propensity for oxide spallation. In contrast, El-Dahshan [20] and Wagner et al. [21], reported that the oxidation kinetics of $\mathrm{Co}-\mathrm{Cr}$ alloys decreased significantly with $\mathrm{Ti}$ additions. The formation of the protective chromia was accelerated with the addition of $\mathrm{Ti}$, with $\mathrm{a}_{\mathrm{Cr}} \mathrm{Ti}_{\mathrm{y}} \mathrm{O}_{\mathrm{z}}$ spinel forming at the metaloxide interface, further blocking diffusion and improving the adhesion of the protective scale. The rapid formation of the chromia scale on $\mathrm{Co}-\mathrm{Cr}$ alloys containing $\mathrm{Ti}$ suggested that the amount of $\mathrm{Cr}$ required to obtain a minimum oxidation rate in $\mathrm{Co}$ alloys could be decreased in the presence of $\mathrm{Ti}$. In commercial chromia forming Ni-base superalloys, Ti has been implicated in the observed acceleration of oxidation damage. In a study by Cruchley et al. [8], it was suggested that the presence of tetravalent $\mathrm{Ti}$ cations within the chromia scale of RR1000 led to a concomitant increase in the defect concentration and, therefore, accelerated growth kinetics.

Whilst, the effects of individual alloying elements on the oxidation characteristics of Ni-based superalloys are well established, the effect of co-additions of key alloying elements is poorly understood. This work aims to outline the oxidation behaviour of nine $\mathrm{Ni}-\mathrm{Co}-\mathrm{Al}-\mathrm{Ti}-\mathrm{Cr}$ alloys at $800{ }^{\circ} \mathrm{C}$. 


\section{Experimental Procedures}

To investigate the oxidation behaviour of $\gamma / \gamma^{\prime}$ alloys from the Ni-Co-Al-Ti-Cr system, a series of nine different compositions were evaluated. The alloys contained three discrete concentrations of $\mathrm{Cr} ; 10,15$ and 20 at.\%, and a total of 10 at.\% $\mathrm{Al}+\mathrm{Ti}$. At each $\mathrm{Cr}$ concentration the $\mathrm{Ni}$ :Co and $\mathrm{Al}$ :Ti ratios varied from 3:1 to 1:1 to 1:3. The nominal compositions of the alloys are given in Table 1. The naming convention of the alloys was chosen to reflect the composition ratios as follows: the first 2 numbers denote the $\mathrm{Cr}$ content in the alloy, for example an alloy containing a nominal 15 at.\% $\mathrm{Cr}$ was named 15\#\#; the subsequent number reflects the ratio of $\mathrm{Ni}: \mathrm{Co}$, number 1 was used to denote a Ni:Co ratio equal to 1:3, 2 denoted Ni:Co ratios equal to $1: 1$ and 3 denoted $\mathrm{Ni}$ :Co ratios equal to $3: 1$; similarly, the last letter was used to identify the Al:Ti ratio, with $a$ indicating a ratio of 1:3, $b$ indicating a ratio of $1: 1$ and $c$ indicating a ratio of 3:1.

$50 \mathrm{~g}$ bars of each alloy were prepared from elemental metals with purities greater than $99.5 \%$ via vacuum arc melting on a water cooled $\mathrm{Cu}$ hearth. Each ingot was inverted and melted a total of five times to improve the homogeneity of the final material. After casting, the bars were encapsulated in quartz tubes under an Aratmosphere and homogenised in the $\gamma$ phase field for $48 \mathrm{~h}$, followed by bench cooling.

$5 \times 5 \times 1 \mathrm{~mm}$ samples were cut from the homogenised bars for thermogravimetric analysis (TGA) and isothermal oxidation testing at $800{ }^{\circ} \mathrm{C}$. This temperature was chosen as it is the target operating temperature of new Ni-based alloys containing elevated concentrations of Co and Ti. Mass gain data for each alloy was acquired using a Setaram Instruments Setsys Evolution TGA during a 100-hour exposure at $800{ }^{\circ} \mathrm{C}$ under air, flowing at $30 \mathrm{ml} \mathrm{min}{ }^{-1}$ and a pressure of 1 bar. The samples were loaded into an alumina crucible and hung from the microbalance. Parabolic rate constants $\left(K_{p}\right)$ were determined for each alloy using the area corrected mass gain $(m)$ and exposure time $(t)$ by fitting the acquired data with the parabolic expression given in Eq. 1 using Wavemetrics Igor Pro [22], in which the

Table 1 Nominal compositions of the alloys evaluated, alongside the actual compositions measured using energy dispersive X-ray spectroscopy (EDX)

\begin{tabular}{|c|c|c|c|c|c|c|c|c|c|c|}
\hline \multirow[t]{2}{*}{ Alloy } & \multicolumn{5}{|c|}{ Nominal composition (at.\%) } & \multicolumn{5}{|c|}{ Actual composition (at.\%) } \\
\hline & $\mathrm{Ni}$ & Co & $\mathrm{Al}$ & $\mathrm{Ti}$ & $\mathrm{Cr}$ & $\mathrm{Ni}$ & Co & $\mathrm{Al}$ & $\mathrm{Ti}$ & $\mathrm{Cr}$ \\
\hline $101 \mathrm{a}$ & 20.0 & 60.0 & 2.5 & 7.5 & 10.0 & 27.2 & 50.7 & 3.1 & 8.1 & 10.9 \\
\hline $102 \mathrm{~b}$ & 40.0 & 40.0 & 5.0 & 5.0 & 10.0 & 39.5 & 38.6 & 5.9 & 5.3 & 10.7 \\
\hline $103 \mathrm{c}$ & 60.0 & 20.0 & 7.5 & 2.5 & 10.0 & 58.2 & 19.6 & 8.6 & 2.8 & 10.8 \\
\hline $151 \mathrm{a}$ & 18.8 & 56.2 & 2.5 & 7.5 & 15.0 & 18.3 & 54.7 & 3.0 & 7.8 & 16.2 \\
\hline $152 b$ & 37.5 & 37.5 & 5.0 & 5.0 & 15.0 & 36.8 & 36.5 & 5.4 & 5.2 & 16.1 \\
\hline $153 \mathrm{c}$ & 56.2 & 18.8 & 7.5 & 2.5 & 15.0 & 54.8 & 18.4 & 8.0 & 2.7 & 16.1 \\
\hline $201 \mathrm{a}$ & 17.5 & 52.5 & 2.5 & 7.5 & 20.0 & 17.2 & 50.3 & 3.1 & 7.9 & 21.5 \\
\hline $202 b$ & 35.0 & 35.0 & 5.0 & 5.0 & 20.0 & 34.3 & 33.5 & 5.7 & 5.2 & 21.3 \\
\hline $203 c$ & 52.5 & 17.5 & 7.5 & 2.5 & 20.0 & 50.6 & 17.4 & 8.5 & 2.5 & 21.0 \\
\hline
\end{tabular}


variable $m_{0}$ accounted for the mass gain associated with the transient oxidation that occurred before parabolic growth was established. For comparison purposes, the data was also analysed using conventional straight line fits through plots of $\mathrm{m}^{2}$ against $t$, from which the gradient of the obtained line corresponds to the $K_{p}$ value.

$$
m=m_{o}+\sqrt{K_{p} t}
$$

Isothermal oxidation testing was also conducted at $800{ }^{\circ} \mathrm{C}$ for $1000 \mathrm{~h}$ under ambient atmospheric conditions. To ensure that any spalled oxides were captured, all samples were placed in alumina crucibles prior to the thermal exposure. Analyses of oxide thickness, internal damage and elemental partitioning between the oxide phases were carried out using a JEOL 5800 scanning electron microscope (SEM) equipped with an Oxford Instruments energy dispersive X-ray spectroscopy (EDX) system.

Bulk alloy compositions were assessed from material in the homogenised state by averaging five $500 \times 500 \mu \mathrm{m}$ area EDX scans. Thermodynamic modeling, using the Thermo-Calc software and the TCNi5 database, was used to predict the equilibrium mole fractions and corresponding elemental concentrations of both the $\gamma$ and $\gamma^{\prime}$ phases at $800{ }^{\circ} \mathrm{C}$.

\section{Results}

\section{Homogenised Alloys and Microstructure}

The nominal compositions of the alloys and those measured using EDX analysis are given in Table 1. The majority of the measured compositions were determined to be within 1 at.\% of the nominal values. However, in alloy 101a (Ni-60Co-2.5Al-

Fig. 1 Secondary electron micrograph of alloy $103 \mathrm{c}(\mathrm{Ni}-$ 20Co-7.5Al-2.5Ti-10Cr) following homogenisation heat treatment showing the typical $\gamma /$ $\gamma^{\prime}$ microstructure (sample etched with $10 \% \mathrm{H}_{3} \mathrm{PO}_{4}$ in $\mathrm{H}_{2} \mathrm{O}$ )

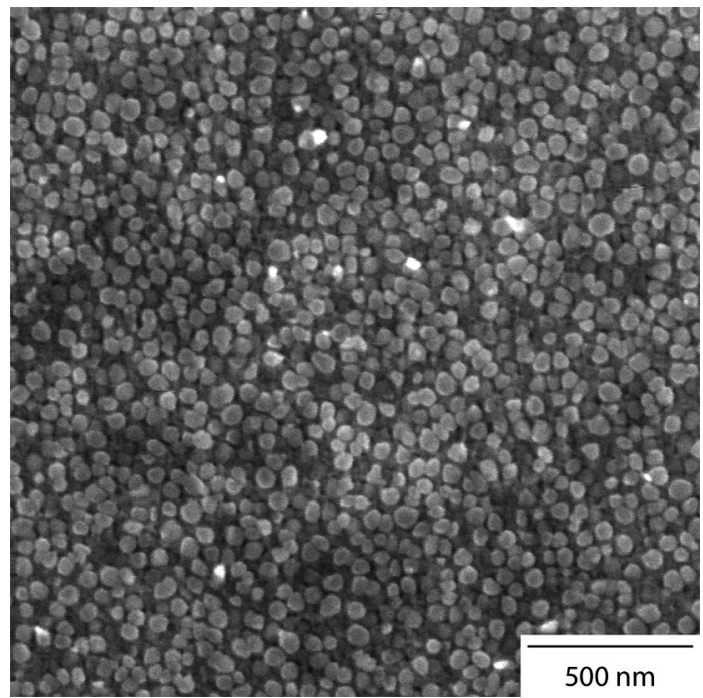


7.5Ti-10Cr) larger deviations were observed, particularly in the concentrations of $\mathrm{Ni}$ and $\mathrm{Co}$, which approached about 10 at.\%. Whilst this was not ideal, the composition of the alloy was still in keeping with the intended systematic variation required for this study. All of the alloys displayed a uniform $\gamma / \gamma^{\prime}$ microstructure [23] following their respective homogenisation heat treatments and a representative example of a secondary electron micrograph from alloy $103 \mathrm{c}(\mathrm{Ni}-20 \mathrm{Co}-7.5 \mathrm{Al}-$ 2.5Ti-10Cr) is shown in Fig. 1 and micrographs from all alloys are presented in the supplementary online information. The $\gamma^{\prime}$ precipitates varied from $\sim 40$ to $65 \mathrm{~nm}$ in diameter for all the alloys examined, and existed in similar volume fractions. Accurate quantification of the $\gamma^{\prime}$ volume fraction was not possible due to the differential etch response of the compositions examined, which resulted in more $\gamma^{\prime}$ being exposed in those alloys that were etched more deeply.

\section{Mass Gain During 100-h Isothermal Exposures}

The area corrected mass gain as a function of time for each of the nine alloys during the 100-h exposure in the TGA is shown in Fig. 2. These results indicate that the alloys containing 10 at.\% $\mathrm{Cr}$ oxidised more than those with higher $\mathrm{Cr}$ contents. The trend between the 15 and 20 at.\% $\mathrm{Cr}$ containing alloys is less clear, as the different alloys are interspersed. This indicated that both the $\mathrm{Al}: \mathrm{Ti}$ and $\mathrm{Ni}: \mathrm{Co}$ ratios influenced the oxidation behaviour of the alloys. However, for a given ratio, lower mass gains were observed with alloys containing higher levels of $\mathrm{Cr}$, for example,

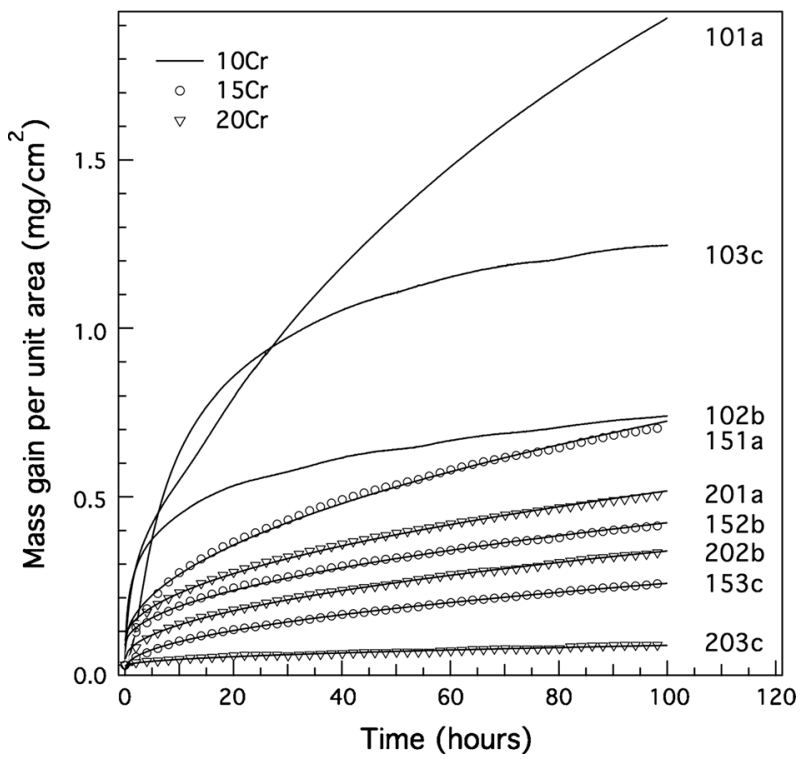

Fig. 2 Mass gain per unit area as a function of time for all alloys during exposure in a TGA at $800{ }^{\circ} \mathrm{C}$. For alloys containing 15 and 20 at. $\% \mathrm{Cr}$, the fitted parabolas are shown overlaid over the TGA data points 
alloy 201a (Ni-52.5Co-2.5Al-7.5Ti-20Cr) exhibited a lower mass gain than alloy 151a (Ni-56.2Co-2.5Al-7.5Ti-15Cr).

The extent to which the observed mass gains could be described by parabolic oxidation kinetics was evaluated by fitting the data obtained with Eq. 1. The area corrected mass gain curves from the alloys containing 10 at.\% $\mathrm{Cr}$ could not be reliably fitted with this function. Alloy $101 \mathrm{a}(\mathrm{Ni}-60 \mathrm{Co}-2.5 \mathrm{Al}-7.5 \mathrm{Ti}-10 \mathrm{Cr})$ oxidised at a rate greater than that described by parabolic kinetics, whilst alloys $102 \mathrm{~b}(\mathrm{Ni}-$ $40 \mathrm{Co}-5 \mathrm{Al}-5 \mathrm{Ti}-10 \mathrm{Cr})$ and $103 \mathrm{c}(\mathrm{Ni}-20 \mathrm{Co}-7.5 \mathrm{Al}-2.5 \mathrm{Ti}-10 \mathrm{Cr})$ exhibited rapid oxidation during the first $10 \mathrm{~h}$ but subsequently gained mass at a far slower rate for the remainder of the test. Conversely, the temporal evolution of the mass gained by the alloys containing 15 and 20 at.\% $\mathrm{Cr}$ were well described by the parabolic relationship. The fitted rate constants $\left(K_{p}\right)$ for these alloys, calculated using the procedures described in the experimental section, are given in Table 2, along with the associated errors, which are extremely small. Given the inadequacy of the fits to the data obtained from the alloys containing 10 at. $\% \mathrm{Cr}$, no rate constants have been included. Whilst the results for the $K_{p}$ values were found to be slightly different depending on the procedure used to calculate the value, the overall ranking trends observed were found to be the same. The rate constants given in Table 2 suggest that alloys with elevated levels of $\mathrm{Ni}$ and $\mathrm{Al}$ have greater oxidation resistance than those containing high levels of Co and Ti. However, this trend does not hold for the mass gained by the alloys containing 10 at.\% Cr, shown in Fig. 2, where alloy 103c (Ni-20Co-7.5Al-2.5Ti-10Cr), which had the greatest $\mathrm{Ni}$ and $\mathrm{Al}$ content gained more mass than alloy $102 \mathrm{~b}(\mathrm{Ni}-40 \mathrm{Co}-5 \mathrm{Al}-5 \mathrm{Ti}-10 \mathrm{Cr})$, which had intermediate $\mathrm{Ni}$ and $\mathrm{Al}$ levels. In addition, it can be seen that, had the tests been extended to times greater than $100 \mathrm{~h}$, larger mass gains would have been likely to be observed from alloy $151 \mathrm{a}(\mathrm{Ni}-56.2 \mathrm{Co}-2.5 \mathrm{Al}-7.5 \mathrm{Ti}-15 \mathrm{Cr})$ than alloy $102 \mathrm{~b}(\mathrm{Ni}-40 \mathrm{Co}-5 \mathrm{Al}-5 \mathrm{Ti}-$

Table 2 Parabolic rate constants and the associated errors obtained from fitting 100-hour exposure TGA data

\begin{tabular}{|c|c|c|}
\hline Alloy & $\begin{array}{l}\text { Parabolic rate constant } \\
\left(\mathrm{mg}^{2} \mathrm{~cm}^{-4} \mathrm{~h}^{-1}\right) \text { (From parabola fits) }\end{array}$ & $\begin{array}{l}\text { Parabolic rate constant } \\
\left(\mathrm{mg}^{2} \mathrm{~cm}^{-4} \mathrm{~h}^{-1}\right) \text { (From line fits) }\end{array}$ \\
\hline $\begin{array}{l}151 \mathrm{a}(\mathrm{Ni}-56.2 \mathrm{Co}- \\
2.5 \mathrm{Al}-7.5 \mathrm{Ti}-15 \mathrm{Cr})\end{array}$ & $4.441 \pm 0.007 \times 10^{-3}$ & $4.886 \pm 0.005 \times 10^{-3}$ \\
\hline $\begin{array}{l}152 \mathrm{~b}(\mathrm{Ni}-37.5 \mathrm{Co}-5 \mathrm{Al}- \\
5 \mathrm{Ti}-15 \mathrm{Cr})\end{array}$ & $1.323 \pm 0.002 \times 10^{-3}$ & $1.616 \pm 0.002 \times 10^{-3}$ \\
\hline $\begin{array}{l}153 \mathrm{c}(\mathrm{Ni}-18.8 \mathrm{Co}- \\
7.5 \mathrm{Al}-2.5 \mathrm{Ti}-15 \mathrm{Cr})\end{array}$ & $6.462 \pm 0.004 \times 10^{-4}$ & $6.047 \pm 0.030 \times 10^{-4}$ \\
\hline $\begin{array}{l}201 \mathrm{a}(\mathrm{Ni}-52.5 \mathrm{Co}- \\
2.5 \mathrm{Al}-7.5 \mathrm{Ti}-20 \mathrm{Cr})\end{array}$ & $1.978 \pm 0.003 \times 10^{-3}$ & $2.421 \pm 0.002 \times 10^{-3}$ \\
\hline $\begin{array}{l}202 \mathrm{~b}(\mathrm{Ni}-35 \mathrm{Co}-5 \mathrm{Al}- \\
5 \mathrm{Ti}-20 \mathrm{Cr})\end{array}$ & $1.035 \pm 0.002 \times 10^{-3}$ & $1.108 \pm 0.007 \times 10^{-3}$ \\
\hline $\begin{array}{l}203 \mathrm{c}(\mathrm{Ni}-17.5 \mathrm{Co}- \\
7.5 \mathrm{Al}-2.5 \mathrm{Ti}-20 \mathrm{Cr})\end{array}$ & $3.708 \pm 0.001 \times 10^{-5}$ & $3.670 \pm 0.001 \times 10^{-5}$ \\
\hline
\end{tabular}



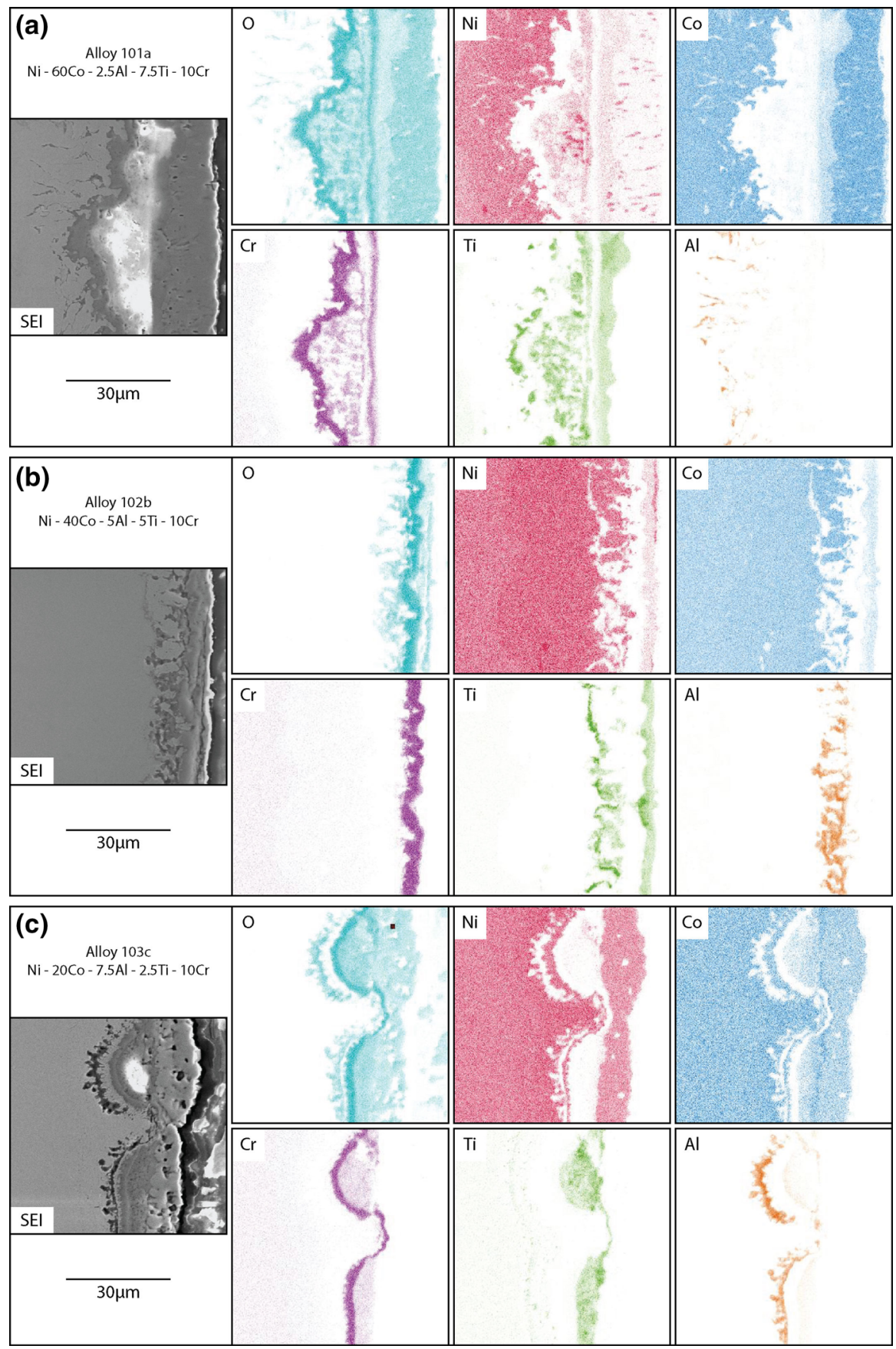

Fig. 3 Secondary electron images of the oxidised surface cross-sections of the alloys containing 10 at. $\%$ $\mathrm{Cr}$ after exposure at $800{ }^{\circ} \mathrm{C}$ for $1000 \mathrm{~h}$ and the corresponding elemental distribution maps 
10Cr). This indicates that $\mathrm{Cr}$ content alone does not provide superior oxidation resistance in alloys based on this quinary system.

\section{Oxide Characterisation Following Exposure for 1000 h}

With the exception of alloy $101 \mathrm{a}(\mathrm{Ni}-60 \mathrm{Co}-2.5 \mathrm{Al}-7.5 \mathrm{Ti}-10 \mathrm{Cr})$, the mass gain data shown in Fig. 2 suggests that steady state oxidation was established in all of the alloys within the $100 \mathrm{~h}$ of TGA testing. Therefore, assuming scale adherence, prolonged exposure to the same condition would be expected to thicken the oxide layers without changing the oxide species formed. Thus, the cross-sections of the oxides developed following the 1000-h isothermal exposure were characterised using SEM. X-ray diffraction was also performed on all samples exposed at $800{ }^{\circ} \mathrm{C}$ for $1000 \mathrm{~h}$. However, due to the complexity of the oxides formed and the similarities of their crystal structures, the unambiguous determination of the phases present was not possible.

Cross-sections of the oxidised surfaces of alloys 101a (Ni-60Co-2.5Al-7.5Ti$10 \mathrm{Cr}), 102 \mathrm{~b}(\mathrm{Ni}-40 \mathrm{Co}-5 \mathrm{Al}-5 \mathrm{Ti}-10 \mathrm{Cr})$ and $103 \mathrm{c}(\mathrm{Ni}-20 \mathrm{Co}-7.5 \mathrm{Al}-2.5 \mathrm{Ti}-10 \mathrm{Cr})$ are shown in Fig. 3, along with the corresponding elemental concentration maps determined by EDX. In all cases, the left hand side of the secondary electron image (labeled SEI) corresponds to the base alloy, whilst the exposed surface is on the right. The six accompanying elemental concentration maps correspond to the five constituent metals and oxygen.

Alloy 101a (Ni-60Co-2.5Al-7.5Ti-10Cr), shown in Fig. 3a, produced a complex layered oxide structure. Within the base material, fingers rich in $\mathrm{Al}$ and $\mathrm{O}$ penetrated $\sim 30 \mu \mathrm{m}$ below an $\sim 5 \mu \mathrm{m}$ thick $\mathrm{Cr}$ and $\mathrm{O}$ rich layer, which also contained significant levels of Ti. Above this layer, a thick, porous region was observed containing a mixture of oxides rich in $\mathrm{Ni}, \mathrm{Cr}$ and $\mathrm{Ti}$. Another $\mathrm{Cr}$ and $\mathrm{O}$ rich layer, $\sim 2 \mu \mathrm{m}$ thick, was present above this, onto which a $\mathrm{Ti}, \mathrm{Ni}$ and $\mathrm{Co}$ oxide was adhered. The surface oxide was predominately Co based, with isolated Ni rich regions.

As can be seen in Fig. 3b, alloy 102b (Ni-40Co-5Al-5Ti-10Cr) exhibited a much simpler oxide structure and a thinner internal damage zone. Sub-scale damage extended $\sim 10 \mu \mathrm{m}$ below the lowest continuous oxide layer and consisted of a $\mathrm{Ti}$ rich phase and thick $\mathrm{Al}$ and $\mathrm{O}$ rich fingers. Above this zone a continuous, reasonably planar chromium oxide, $\sim 5 \mu \mathrm{m}$ thick, had formed, on top of which was the surface oxide, rich in $\mathrm{Ni}$, $\mathrm{Co}$ and $\mathrm{Ti}$.

The overall oxidation damage observed in alloy $103 \mathrm{c}(\mathrm{Ni}-20 \mathrm{Co}-7.5 \mathrm{Al}-2.5 \mathrm{Ti}-$ $10 \mathrm{Cr})$, Fig. 3c, was much more extensive than that seen in alloy $102 \mathrm{~b}(\mathrm{Ni}-40 \mathrm{Co}-$ 5Al-5Ti-10Cr). A thin Ti rich layer was the deepest observed feature, above which had formed $\mathrm{Al}$ and $\mathrm{O}$ rich fingers, approximately $\sim 5 \mu \mathrm{m}$ in length. A continuous chromium oxide layer, $\sim 2 \mu \mathrm{m}$ thick, was observed above the fingers, but in contrast to alloy $102 \mathrm{~b}(\mathrm{Ni}-40 \mathrm{Co}-5 \mathrm{Al}-5 \mathrm{Ti}-10 \mathrm{Cr})$ this layer was highly rumpled, more akin to that seen in alloy 101a (Ni-60Co-2.5Al-7.5Ti-10Cr) . Similarly, a thick mixed oxide layer was observed in alloy $103 \mathrm{c}(\mathrm{Ni}-20 \mathrm{Co}-7.5 \mathrm{Al}-2.5 \mathrm{Ti}-10 \mathrm{Cr})$, although in this case the region was rich in $\mathrm{Co}, \mathrm{Cr}$ and $\mathrm{Ti}$. The surface oxide in alloy 

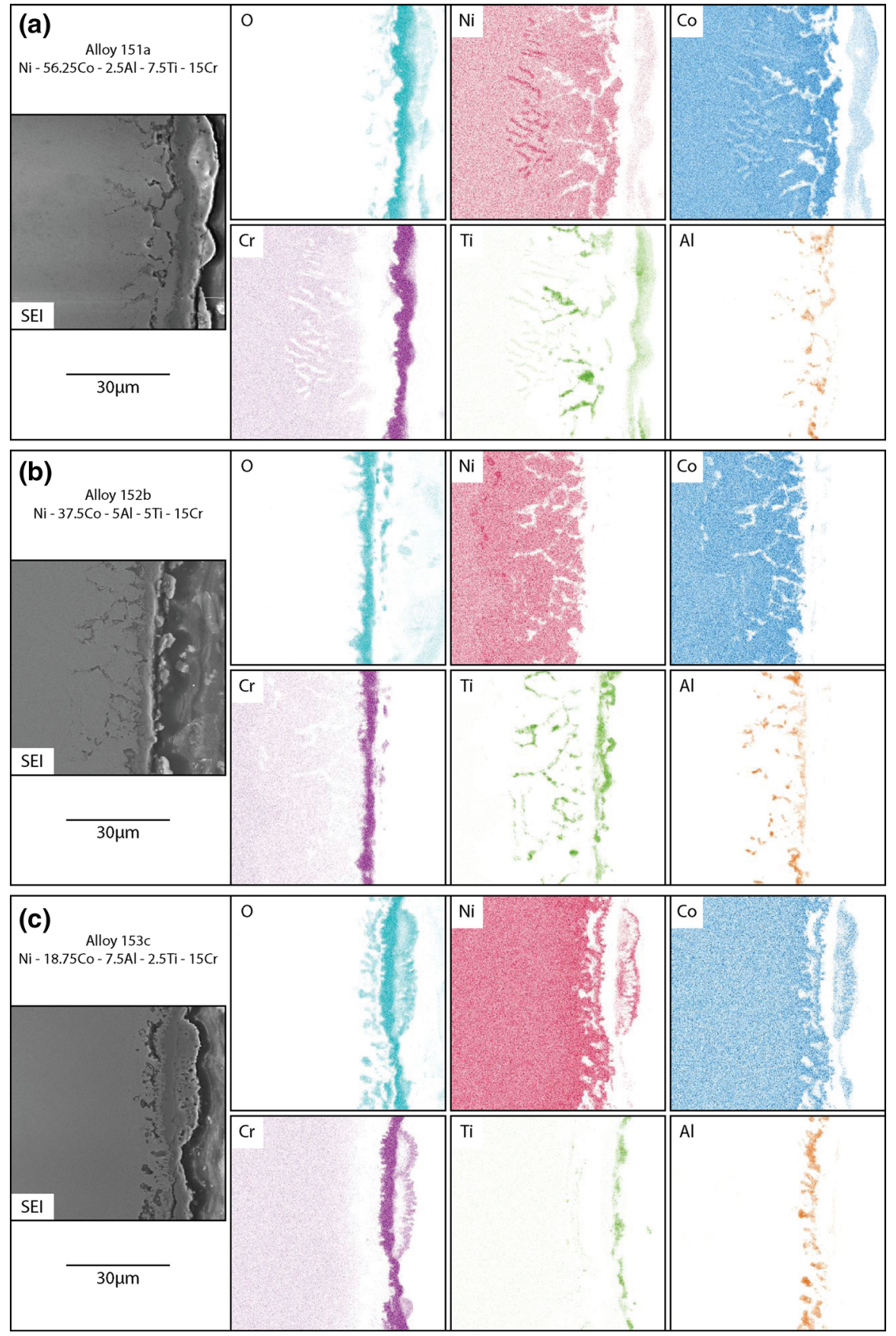

Fig. 4 Secondary electron images of the oxidised surface cross-sections of the alloys containing 15 at. $\%$ $\mathrm{Cr}$ after exposure at $800{ }^{\circ} \mathrm{C}$ for $1000 \mathrm{~h}$ and the corresponding elemental distribution maps 

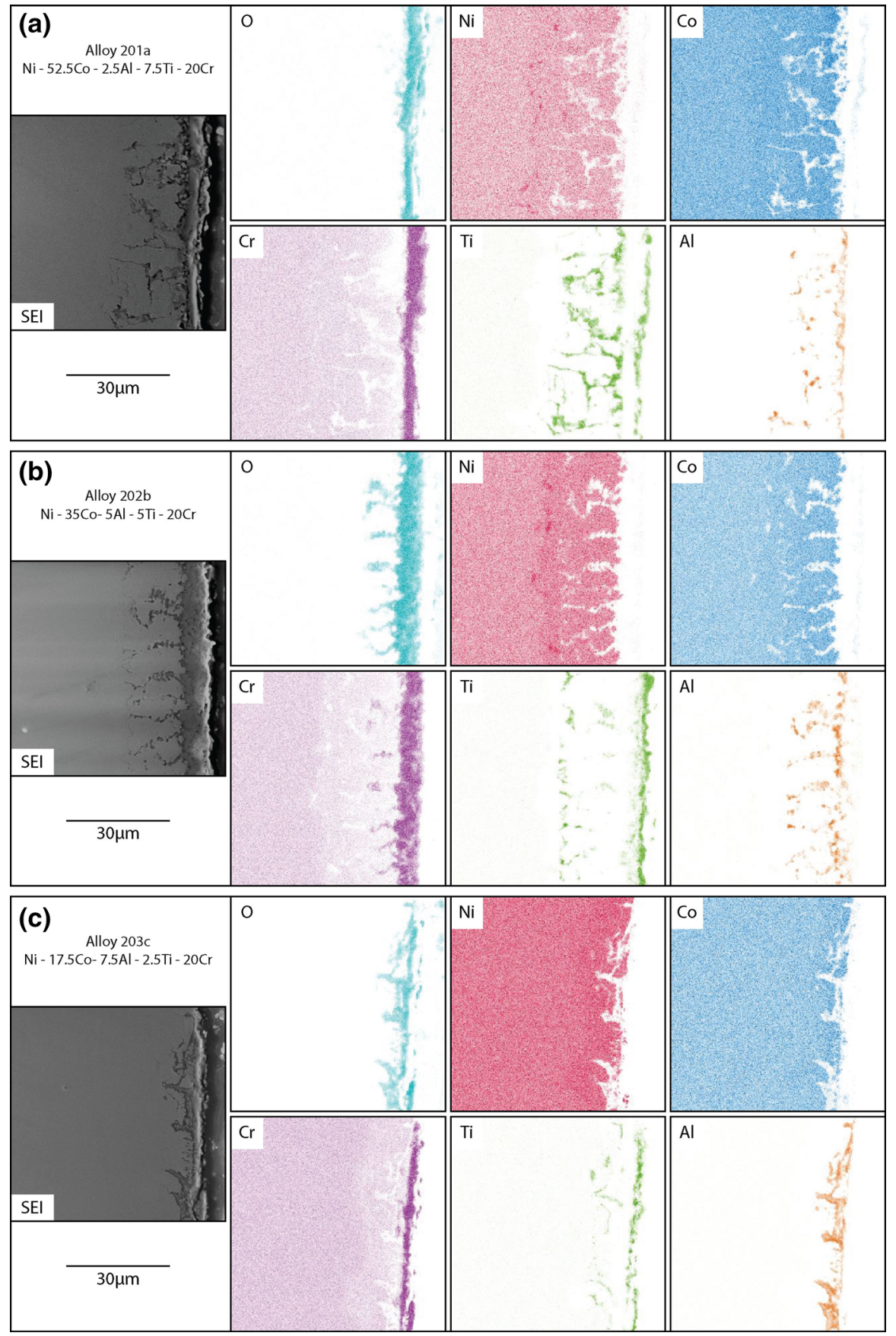

Fig. 5 Secondary electron images of the oxidised surface cross-sections of the alloys containing 20 at. $\%$ $\mathrm{Cr}$ after exposure at $800{ }^{\circ} \mathrm{C}$ for $1000 \mathrm{~h}$ and the corresponding elemental distribution maps 
$103 \mathrm{c}(\mathrm{Ni}-20 \mathrm{Co}-7.5 \mathrm{Al}-2.5 \mathrm{Ti}-10 \mathrm{Cr})$ was found to be highly porous and based on $\mathrm{Ni}$ and Co.

The oxide formations observed in the alloys containing 15 at.\% $\mathrm{Cr}$ are shown in Fig. 4 and exhibited simpler and thinner oxide layers than those of the 10 at.\% $\mathrm{Cr}$ series. Alloy 151a (Ni-56.2Co-2.5Al-7.5Ti-15Cr), Fig. 4a, showed Ni rich fingerlike features approximately $40 \mu \mathrm{m}$ below the surface. In contrast to the base alloy, these features were depleted in both $\mathrm{Co}$ and $\mathrm{Cr}$ but showed elevated levels of Ti. Critically, no evidence of oxygen enrichment was detected at this depth and, therefore, these features were believed to be an intermetallic phase rather than an oxide. Above these features, a $\sim 20 \mu \mathrm{m}$ thick region that contained two interpenetrating phases was observed, one rich in $\mathrm{Ti}$ and the other rich in $\mathrm{Al}$ and O. A continuous chromium oxide layer, $\sim 6 \mu \mathrm{m}$ thick, had formed on top of this region, above which the surface oxide was found, rich in $\mathrm{Ni}, \mathrm{Co}$ and $\mathrm{Ti}$.

The oxides formed on alloy $152 \mathrm{~b}(\mathrm{Ni}-37.5 \mathrm{Co}-5 \mathrm{Al}-5 \mathrm{Ti}-15 \mathrm{Cr})$, Fig. 4b, showed many similarities with those formed on alloy $151 \mathrm{a}(\mathrm{Ni}-56.2 \mathrm{Co}-2.5 \mathrm{Al}-7.5 \mathrm{Ti}-15 \mathrm{Cr})$. Approximately $30 \mu \mathrm{m}$ beneath the free surface, features enriched in $\mathrm{Ni}$ and depleted in $\mathrm{Co}$ and $\mathrm{Cr}$ could be observed. Since no $\mathrm{O}$ was observed at this depth, these features were assumed to be an intermetallic phase. Above this intermetallic phase, an extensive sub-scale network, $\sim 25 \mu \mathrm{m}$ thick, comprising $\mathrm{Ti}$ and $\mathrm{Al}$ rich phases could be seen. A continuous, planar chromium oxide layer, $\sim 4 \mu \mathrm{m}$ thick, was observed above the sub-scale layers. Unlike any of the preceding alloys, the surface oxide observed on alloy $152 \mathrm{~b}(\mathrm{Ni}-37.5 \mathrm{Co}-5 \mathrm{Al}-5 \mathrm{Ti}-15 \mathrm{Cr})$ consisted solely of $\mathrm{Ti}$ and $\mathrm{O}$.

The extent of oxidation damage observed in alloy $153 \mathrm{c}(\mathrm{Ni}-18.8 \mathrm{Co}-7.5 \mathrm{Al}-$ 2.5Ti-15Cr), Fig. 4c, was the smallest of the alloys containing 15 at.\% Cr. An extremely thin band of Ti rich particles were detected at a depth $\sim 20 \mu \mathrm{m}$ below the surface, over which an $\sim 5 \mu \mathrm{m}$ thick region of $\mathrm{Al}$ and $\mathrm{O}$ rich fingers was observed. A continuous chromium oxide layer had formed above the fingers, on top of which mixed oxide surface blisters had developed, rich in $\mathrm{Ni}, \mathrm{Co}, \mathrm{Cr}$ and $\mathrm{Ti}$.

The oxide scales formed in the alloys containing 20 at.\% $\mathrm{Cr}$ are shown in Fig. 5. Extensive sub-scale damage was observed in alloy 201a (Ni-52.5Co-2.5Al-7.5Ti$20 \mathrm{Cr}$ ), Fig. 5a, which penetrated to a maximum depth of $\sim 25 \mu \mathrm{m}$ below the surface. At the greatest depth, small features rich in $\mathrm{Ni}$ and lean in $\mathrm{Co}$ and $\mathrm{Cr}$ were seen. Above these features, the damaged region contained a network of Ti rich particles interspersed with an $\mathrm{Al}$ rich phase. No evidence of elevated oxygen concentrations were found at this depth. Above this region a continuous, planar chromium oxide layer, $\sim 5 \mu \mathrm{m}$ thick, had formed, on top of which a discontinuous $\mathrm{Ti}$ and $\mathrm{O}$ based film was observed.

The oxide scale profile observed in alloy $202 \mathrm{~b}(\mathrm{Ni}-35 \mathrm{Co}-5 \mathrm{Al}-5 \mathrm{Ti}-20 \mathrm{Cr}$ ), Fig. 5b, was similar to that of alloy 201a (Ni-52.5Co-2.5Al-7.5Ti-20Cr). Small features rich in $\mathrm{Ni}$ and lean in $\mathrm{Co}$ and $\mathrm{Cr}$ were again seen at the greatest depth. The overlaid sub-scale damaged region extended to $\sim 25 \mu \mathrm{m}$ below the surface and had Ti rich particles at its greatest depth, followed by fingers, some of which were $\mathrm{Al}$ rich. Although, unlike alloy 201a (Ni-52.5Co-2.5Al-7.5Ti-20Cr), some fingers with elevated levels of $\mathrm{Al}, \mathrm{Cr}$ and $\mathrm{O}$ were also observed. Above the fingers, an 
$\sim 7 \mu \mathrm{m}$ thick chromium oxide layer was observed on top of which a thin, near continuous, Ti rich surface oxide layer was found.

Alloy 203c (Ni-17.5Co-7.5Al-2.5Ti-20Cr), Fig. 5c, displayed the least oxidation damage of any of the alloys in this study. The internal damage only reached $\sim 10 \mu \mathrm{m}$ below the surface and comprised a thin Ti rich layer below $\mathrm{Al}$ and $\mathrm{O}$ rich fingers. A thin, $\sim 2 \mu \mathrm{m}$, continuous chromium oxide layer was observed above the damaged sub-scale region, followed by a discontinuous Ti rich oxide film.

\section{Discussion}

The microstructures of all of the alloys examined comprised uniform dispersions of $\gamma^{\prime}$ precipitates within the $\gamma$ matrix. Given the similarity between the sizes of the $\gamma^{\prime}$ precipitates and their volume fractions, it is believed that microstructural differences did not contribute significantly to the oxidation characteristics of the alloys examined. Instead, the mass gains recorded using TGA analysis and the nature of the oxide strata were controlled by the alloy compositions.

TGA is a popular technique for the evaluation of the oxidation kinetics of alloys. However, care must be taken when analysing TGA data, as the results can be significantly influenced by the heating rates, furnace atmosphere and gas flow-rates, as well as sample related factors such as geometry and surface finish. Therefore, the TGA data reported was only used to rank the relative behaviour of the alloys.

The TGA results presented in Fig. 2 indicated that, in general, increasing the $\mathrm{Cr}$ concentration, whilst keeping the ratios of all other elements constant, resulted in a lower mass gain per unit area, as well as a lower parabolic oxidation rate constant. In addition, with the exception of the alloys containing 10 at. $\% \mathrm{Cr}$, higher $\mathrm{Ni}$ and $\mathrm{Al}$ contents were more resistant to oxidation than those with elevated levels of Co and Ti. For all alloys, the measured mass gains were observed to be consistent with the thickness of the external oxide scales. However, the depth of sub surface oxidation damage observed on the cross sections of the samples was not directly correlated with the mass gains recorded by TGA, with extensive sub scale damage being observed in all alloys except those containing the highest $\mathrm{Ni}$ and $\mathrm{Al}$ contents, series \#\#3c (7.5Al-2.5Ti). The cross sections of all of the oxidised samples, shown in Figs. 3, 4, and 5, contained continuous chromium oxide layers. The alloys containing the highest concentrations of $\mathrm{Ni}$ and $\mathrm{Al}$, series \#\#3c (7.5Al-2.5Ti), exhibited substantially thinner chromium oxide scales than those containing higher Co and Ti levels, series \#\#1a (2.5Al-7.5Ti) and \#\#2b (5Al-5Ti). This result is consistent with the high solubility of Ti in chromia [24]. As a p-type metal deficient semiconductor, the accommodation of $\mathrm{Ti}^{4+}$ cations requires a concomitant increase in the number density of vacancies $[25,26]$. This increases the ionic conductivity of the oxide scale, leading to faster oxidation rates and thicker chromia scales.

Immediately beneath the chromium oxide scale, internal aluminium oxide and nitrides were observed to form in all alloys. This is to be expected as the partial pressures of oxygen and nitrogen at which these species form are significantly lower than that of their chromium counterparts [27]. Critically, a continuous alumina layer was not observed to form in any of the alloys tested. Alongside the Al containing 
particles, Ti rich features were observed. The location of these features did not correspond to elevated concentrations of oxygen, and therefore, they were believed to be nitrides. In Fig. 6, an example of the elemental maps of $\mathrm{Ti}, \mathrm{Al}$ and $\mathrm{N}$ are shown for alloy $152 \mathrm{~b}(\mathrm{Ni}-37.5 \mathrm{Co}-5 \mathrm{Al}-5 \mathrm{Ti}-15 \mathrm{Cr})$, confirming the presence of elevated concentrations of nitrogen in these regions. This result is also consistent with other studies of the oxidation behaviour of Ni-based superalloys [8, 14, 28, 29]. The work of Krupp et al. [30, 31] indicated that increased Cr concentrations may result in nitridation to a greater depth in the alloy. Their observation is consistent with the results obtained from the \#\#1a (2.5Al-7.5Ti) and \#\#2b (5Al-5Ti) alloys, which showed systematically more prevalent $\mathrm{Ti}$ nitrides in the subscale with increased $\mathrm{Cr}$ concentration. Although, this trend was less apparent in the \#\#3c (7.5Al-2.5Ti) alloys, where the occurrence of this phase was less clear owing to the lower concentration of $\mathrm{Ti}$ in these alloys.

In the \#\#1a (2.5Al-7.5Ti) alloys, which contained the highest levels of $\mathrm{Ti}$, particles rich in $\mathrm{Ni}$ and $\mathrm{Ti}$ were observed to form beneath the network of nitrides and aluminium oxide. This phase was believed to be the intermetallic $\eta-\mathrm{Ni}_{3} \mathrm{Ti}$ phase. In this region, internal oxidation and nitridation may reduce the local Al concentration in the alloy to a level that allows this phase to form [32]. The lower $\mathrm{Cr}$ concentrations observed in this phase are also consistent with it being $\eta$, as this phase is known to have limited solubility for $\mathrm{Cr}$ [33]. Similarly, examination of the $\mathrm{Ni}-\mathrm{Ti}$ binary phase diagrams suggested that the $\eta-\mathrm{Ni}_{3} \mathrm{Ti}$ phase was the only possible phase at the concentrations of Ti and Ni observed [34]. Whilst not an oxide or nitride, this phase forms as a direct result of the internal oxidation and nitridation and is therefore considered as part of the oxidation-induced damage in the alloy. Occurrences of this phase were also observed in the \#\#2b (5Al-5Ti) alloys, although they were far less extensive than those in the \#\#1a (2.5Al-7.5Ti) alloys as a result of their lower overall $\mathrm{Ti}$ concentration.

Thick Ni, Co and Ti rich oxides were observed to form over the chromium oxide layers in the alloys containing 10 and 15 at.\% $\mathrm{Cr}$, with the exception of alloy $152 \mathrm{~b}$ (Ni-37.5Co-5Al-5Ti-15Cr). These were believed to be spinel-type $\left(\mathrm{AB}_{2} \mathrm{X}_{4}\right)$ oxides, however, their crystallographic nature could not be determined. Notably, the alloys that formed this layer also showed pronounced $\mathrm{Cr}$ depletion regions beneath the chromium oxide scale. This suggests that the $\mathrm{Cr}$ concentrations in these alloys were insufficient to readily form the chromium oxide layer during the transient
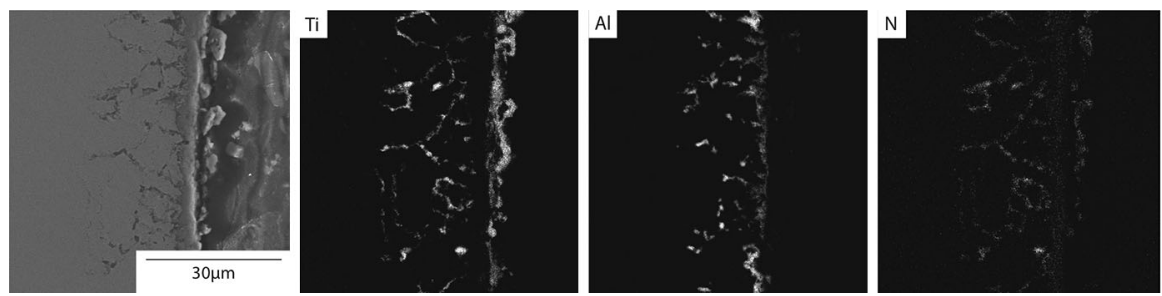

Fig. 6 Secondary electron image of the oxidised surface cross-section of alloy $152 \mathrm{~b}(\mathrm{Ni}-37.5 \mathrm{Co}-5 \mathrm{Al}-$ $5 \mathrm{Ti}-15 \mathrm{Cr}$ ) after exposure at $800{ }^{\circ} \mathrm{C}$ for $1000 \mathrm{~h}$ and the corresponding elemental distribution maps for Ti, $\mathrm{Al}$ and $\mathrm{N}$ 
stages of oxidation, allowing significant oxidation of the other species present in the alloy before the continuous chromium oxide layer was established. In addition, alloys 101a (Ni-60Co-2.5Al-7.5Ti-10Cr) and 103c (Ni-20Co-7.5Al-2.5Ti-10Cr) showed large amplitude rippling of the oxide scale. This phenomenon is related to the formation of the $\mathrm{Cr}$ depleted layer and is known to occur when diffusion through the chromium oxide is faster than the supply of $\mathrm{Cr}$ from the base alloy [13]. In such circumstances, a region with a steep chromium concentration gradient will develop and any perturbations in the oxide-metal interface will be unstable and grow into the alloy. The lack of oxide rippling in alloy $102 \mathrm{~b}(\mathrm{Ni}-40 \mathrm{Co}-5 \mathrm{Al}-5 \mathrm{Ti}-10 \mathrm{Cr})$, the absence of a Ni, Co and $\mathrm{Ti}$ rich oxide above the chromium oxide scale in alloy $152 \mathrm{~b}$ (Ni-37.5Co-5Al-5Ti-15Cr) and the shallower $\mathrm{Cr}$ depleted regions observed in all of the alloys \#\#2b (5Al-5Ti) are interesting, as all of these observations suggest that $\mathrm{Cr}$ is more mobile in these alloys than their \#\#1a (2.5Al-2.5Ti) and \#\#3c (7.5Al2.5Ti) counterparts. This suggests that the $\mathrm{Cr}$ activity in these alloys does not vary linearly with the Ni:Co ratio.

The apparent increased mobility of $\mathrm{Cr}$ in the \#\#2b (5Al-5Ti) alloys was rationalised through calculations of the phase equilibria of the alloys. Thermodynamic calculations were performed using the Thermo-Calc software with the TCNi5 thermodynamic database. The concentrations of $\mathrm{Cr}$ predicted to be in the $\gamma$ matrix and the mole fraction of $\gamma^{\prime}$ precipitates are presented in Table 3. Interestingly, the $\mathrm{Cr}$ concentration predicted in the $\gamma$ matrix was always highest in the \#\#2b (5Al-5Ti) series, for any given $\mathrm{Cr}$ concentration in the alloy. This could arise as a result of a higher volume fraction of $\gamma^{\prime}$ particles in the \#\#2b (5Al-5Ti) alloys, as this phase is known to reject $\mathrm{Cr}$ into the $\gamma$ matrix, or alternatively, elevated $\mathrm{Cr}$ levels might arise as a result of changes in the elemental partitioning between the $\gamma$ and $\gamma^{\prime}$ phases. From Table 3, the mole fraction of $\gamma^{\prime}$ precipitates in the material is predicted to be higher in the \#\#2b (5Al-5Ti) type alloys, although, this is only a marginal difference when compared to the values obtained in the \#\#3c (7.5Al-2.5Ti) type alloys, suggesting that a combination of both mechanisms is in effect. However, care is required in extending this argument across the entire range of alloys considered as

Table 3 Thermodynamic predictions using Thermo-Calc with the TCNi5 database of the Cr concentration in the $\gamma$ matrix and the mole fraction of $\gamma^{\prime}$ precipitates

\begin{tabular}{lll}
\hline Alloy & $\mathrm{Cr}$ in $\gamma$ matrix (at.\%) & Mole fraction of $\gamma^{\prime}$ precipitates (\%) \\
\hline 101a (Ni-60Co-2.5Al-7.5Ti-10Cr) & 12.29 & 22.95 \\
102b (Ni-40Co-5Al-5Ti-10Cr) & 13.87 & 30.37 \\
103c (Ni-20Co-7.5Al-2.5Ti-10Cr) & 13.13 & 28.62 \\
151a (Ni-56.2Co-2.5Al-7.5Ti-15Cr) & 19.47 & 28.00 \\
152b (Ni-37.5Co-5Al-5Ti-15Cr) & 21.85 & 33.57 \\
153c (Ni-18.8Co-7.5Al-2.5Ti-15Cr) & 21.08 & 33.22 \\
201a (Ni-52.5Co-2.5Al-7.5Ti-20Cr) & 26.54 & 31.90 \\
202b (Ni-35Co-5Al-5Ti-20Cr) & 30.11 & 35.52 \\
203c (Ni-17.5Co-7.5Al-2.5Ti-20Cr) & 29.13 & 35.05 \\
\hline
\end{tabular}


many of the alloys have compositions outside the assessed ranges of the databases used for the thermodynamic calculations. This limitation is most evident in alloy 101a (Ni-60Co-2.5Al-7.5Ti-10Cr), which is predicted to have a $\gamma^{\prime}$ volume fraction significantly lower than that of the other alloys, despite microstructural observations indicating that the $\gamma^{\prime}$ volume fraction was similar in all alloys.

\section{Conclusions}

In this study, the oxidation characteristics of a series of $\gamma / \gamma^{\prime}$ alloys based on the $\mathrm{Ni}-$ $\mathrm{Co}-\mathrm{Al}-\mathrm{Ti}-\mathrm{Cr}$ quinary system have been investigated. For a given $\mathrm{Al}$ and $\mathrm{Ti}$ content, increasing $\mathrm{Cr}$ concentrations from 10 to 20 at.\%, at the expense of $\mathrm{Ni}$ and $\mathrm{Co}$, resulted in a systematic reduction in the mass gained after a 100-hour exposure. However, alloys rich in $\mathrm{Ni}$ and $\mathrm{Al}$ gained less mass than those rich in $\mathrm{Co}$ and $\mathrm{Ti}$ for a given $\mathrm{Cr}$ concentration. The overall mass gains were observed to be consistent with the thicknesses of the external oxide scales, but not with the depth of internal damage. Therefore, these results illustrate that oxidation resistance is not simply a function of $\mathrm{Cr}$ content in these alloys. Alloys with equal concentrations of $\mathrm{Ni}$ and $\mathrm{Co}$ and $\mathrm{Al}$ and $\mathrm{Ti}$ showed evidence of higher $\mathrm{Cr}$ mobilities than either $\mathrm{Ni}$ and $\mathrm{Al}$ rich or Co and Ti rich compositions. Thermodynamic calculations suggested that this effect arose as a result of anomalously high $\mathrm{Cr}$ concentrations in the former alloys, caused by a synergistic effect of the increased $\gamma^{\prime}$ mole fraction, which rejects $\mathrm{Cr}$ into the matrix, and the modification of the elemental partitioning behaviour of the alloy.

Acknowledgments The authors would like to thank Mr. K.A. Roberts and Dr. H.T. Pang for experimental assistance. This work was supported by the Rolls-Royce plc / EPSRC Strategic Partnership under EP/H022309/1, EP/H500375/1 and EP/M005607/1. The original research data is available at https://www.repository.cam.ac.uk/handle/1810/25304.

Open Access This article is distributed under the terms of the Creative Commons Attribution 4.0 International License (http://creativecommons.org/licenses/by/4.0/), which permits unrestricted use, distribution, and reproduction in any medium, provided you give appropriate credit to the original author(s) and the source, provide a link to the Creative Commons license, and indicate if changes were made.

\section{References}

1. C. Y. Cui, A. Sato, Y. F. Gu, D. H. Ping, and H. Harada, Metallurgical and Materials Transactions A 37, 3183 (2006). http://www.springerlink.com/index/B155R454MX262J60.pdf. Accessed Nov 15, 2011.

2. N. G. Jones, K. A. Christofidou, P. M. Mignanelli, J. P. Minshull, M. C. Hardy and H. J. Stone, Materials Science and Technology 30, 1853 (2014). doi:10.1179/1743284714Y.0000000509.

3. A. Karabela, L. G. Zhao, B. Lin, J. Tong and M. C. Hardy, Materials Science and Engineering A 567, 46 (2013). doi:10.1016/j.msea.2012.12.088.

4. C. J. McMahon, Materials Science and Engineering 13, 295 (1974). doi:10.1016/00255416(74)90202-X.

5. J. A. Pfaendtner and J. J. McMahon, Acta Materialia 49, 3369 (2001). doi:10.1016/S13596454(01)00005-2.

6. G. C. Wood, Oxidation of Metals 2, 11 (1970). doi:10.1007/BF00603581. 
7. S. Cruchley, M. P. Taylor, H. E. Evans, M. C. Hardy and D. J. Child, Materials Science and Technology 30, 1884 (2014). doi:10.1179/1743284714Y.0000000541.

8. S. Cruchley, H. E. Evans, M. P. Taylor, M. C. Hardy and S. Stekovic, Corrosion Science 75, 58 (2013). doi:10.1016/j.corsci.2013.05.016.

9. A. Encinas-Oropesa, G. L. Drew, M. C. Hardy, A. J. Leggett, J. R. Nicholls and N. J. Simms, Eleventh International Symposium 2008, 609 (2008). doi:10.7449/2008/Superalloys_2008_609_618.

10. M. P. Taylor, H. E. Evans, S. Stekovic and M. C. Hardy, Materials at High Temperatures 29, 145 (2012). doi:10.3184/096034012X13341417107382.

11. L. Zheng, M. Zhang and J. Dong, Applied Surface Science 256, 7510 (2010). doi:10.1016/j.apsusc. 2010.05.098.

12. D. Kim, C. Jang and W. S. Ryu, Oxidation of Metals 71, 271 (2009). doi:10.1007/s11085-009-9142-5.

13. R. G. Wallwork, Reports On Progress 39, 401 (1976).

14. J. H. Chen, P. M. Rogers and J. A. Little, Oxidation of Metals 47, 381 (1997). doi:10.1007/ BF02134783.

15. C. Wagner and K. E. Zimens, Acta Chemica Scandinavica, 547 (1947)

16. A. Preece and G. Lucas, Journal of the Institute of Metals 81, 219 (1952).

17. C. S. Giggins and F. S. Pettit, Journal of the Electrochemical Society 118, 1782 (1971).

18. A. F. Giamei, D. D. Pearson, and D. L. Anton, Gamma/gamma': the key to superalloy behavior, in Materials Research Society Symposium Proceedings, 293 (1985).

19. H. Nagai and M. Okabayashi, Transactions of the Japan Institute of Metals 22, 691 (1981).

20. M. E. El-Dahshan, Transactions of the Japan Institute of Metals 22, 25 (1981).

21. G. P. Wagner and G. Simkovich, Oxidation of Metals 26, 139 (1986). doi:10.1007/BF00664278.

22. WaveMetrics, Igor Pro (1989).

23. C. T. Sims, N. S. Stoloff, and W. C. Hagel, Superalloys II (Wiley, New York, 1987)

24. A. Naoumidis, H. A. Schulze and C. García-Rosales, Materials Science Forum 79-82, 691 (1991). doi:10.4028/www.scientific.net/MSF.79-82.691.

25. A. N. Blacklocks, A. Atkinson, R. J. Packer, S. L. P. Savin and A. V. Chadwick, Solid State Ionics 177, 2939 (2006). doi:10.1016/j.ssi.2006.08.028.

26. A. Atkinson, M. R. Levy, S. Roche and R. A. Rudkin, Solid State Ionics 177, 1767 (2006). doi:10. 1016/j.ssi.2005.11.015.

27. H. J. T. Ellingham, Journal of the Society Chemical Industry, 63 (1944).

28. D. L. Douglass, Oxidation of Metals 44, 81 (1995). doi:10.1007/BF01046724.

29. U. Krupp and H. J. Christ, Metallurgical and Materials Transactions A 31, 47 (2000).

30. U. Krupp and H. J. Christ, Oxidation of Metals 52, 277 (1999).

31. U. Krupp, Oxidation of Metals 52, 299 (1999). doi:10.1023/A:1018895628849.

32. K. B. Povarova, A. V. Antonova, B. I. Burmistrov and O. A. Skachkov, Metally. 3, 75 (2005).

33. J. A. van Beek, A. A. Kodentsov and F. J. J. van Loo, Journal of Alloys and Compounds 270, 218 (1998).

34. Y. Ohtani, M. Tamano and M. Hasebe, CALPHAD 28, 177 (2004). 